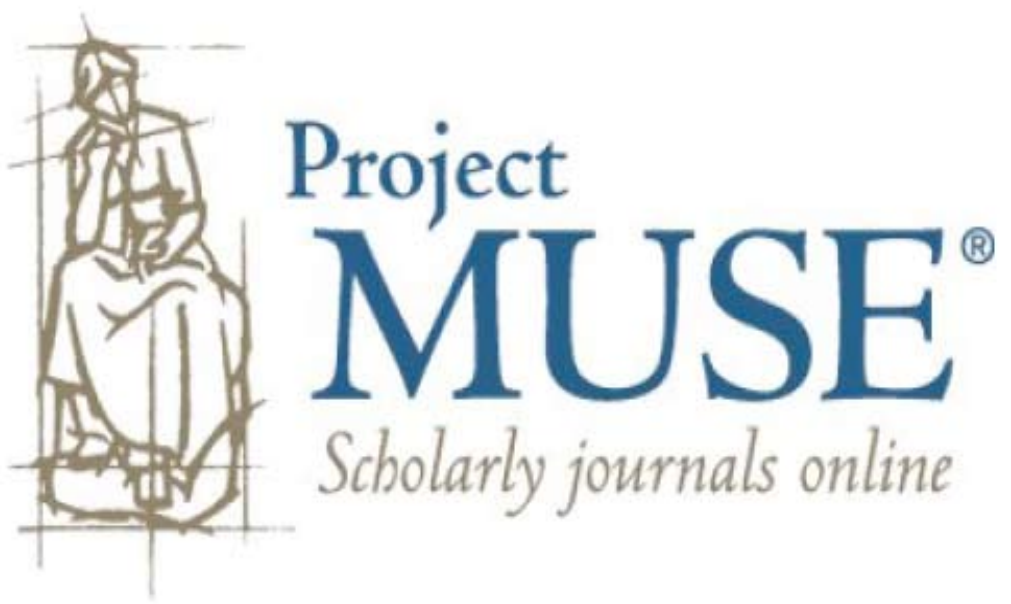




\title{
Dissonant Voices in Richard Rodriguez's Hunger of Memory and Luce Irigaray's This Sex Which Is Not One
}

\author{
Nidesh Lawtoo
}

With the publication of Days of Obligation and, more recently, Brown, Richard Rodriguez's scholarship has begun to recognize the theoretical import inherent in the Hispanic writer's autobiographical essays. Juan de Castro most clearly makes this point as he states that "[t]oday, like Gloria Anzaldúa or José David Saldívar, Rodriguez can be classified as a theorist of the borderlands" (102). This positive assessment of Rodriguez concerns mainly his two latest works which are often read as representing a radical rupture with his first autobiographical essay, Hunger of Memory. ${ }^{1}$ In what follows I take de Castro's assessment of Rodriguez as a "theorist" seriously by uncovering the theory of borderland identities, which I consider to be already implicit in his first and most controversial book. ${ }^{2}$ More precisely, I compare Rodriguez's epistemology of in-between identities with the theory of subjectivity advocated by the French feminist poststructuralist philosopher and psychoanalyst, Luce Irigaray in This Sex Which Is Not One. If on the one hand, Hunger of Memory can be read as a literary text with theoretical implications, then on the other hand, Margaret Whitford-one of Irigaray's most informed American critics-affirms that "we should treat Irigaray's work as literature" (23). ${ }^{3}$ By cross-reading these two literary / theoretical texts I begin to delineate the points of divergence and the points of convergence of two epistemic models of subjectivity. Put differently, Rodriguez and Irigaray's theoretical opposition and proximity, I will argue, can be found at the complex intersection between literature and theory. Thus, implicit in this double-reading strategy is an attempt at once to theorize and to interpret.

It should first be noted that Rodriguez's Hunger of Memory is based upon epistemic, cultural, and political premises that are inimical, if not 
antithetical, to those articulated by Luce Irigaray's in This Sex Which Is Not One. In fact, Rodriguez's stand against bilingual education is consistent with his argument in favor of the "necessity of assimilation" (26) of ethnic minorities to the totalizing unity which is implicit in American national identity. His theoretical premises are grounded upon what Irigaray-speaking from the perspective of sexual rather than racial identity-defines as the "domination of the philosophic logos" which "reduce[s] all others to the economy of the Same" (This Sex, 74). Irigaray's theoretical position counters the theory of identity implicit in Rodriguez's autobiography. In fact, speaking from the opposite side of the spectrum, Irigaray promotes a conception of the subject rooted in difference and multiplicity which resists assimilation to the hegemonic (patriarchal) order. Briefly put, if Rodriguez's promotion of assimilation betrays a "desire for 'sameness,"' Irigaray advocates a "desire for 'otherness"' (This Sex, 130).

What is at stake in the confrontation of the Chicano writer and the radical feminist is a clash of theoretical perspectives concerning the subaltern subject as well as its problematic relation to both "sameness" and "difference." And in what follows I begin to explore the generative tensions arising from this theoretical clash. More precisely, I consider Rodriguez and Irigaray's economies of "sameness" and "difference" that sustain their conceptions of identity, in order to initiate a dialogue between these two thinkers. This confrontation will first allow me to point out the limitations inherent in Rodriguez's epistemology of "sameness" and, subsequently, to tease out the radical conclusions that are glimpsed, rather than taken hold of, in his first autobiography; while, at the same time, indicating the limits of Irigaray's radicalism. In brief, I will begin to open up a space of inquiry concerning in-between subjectivity by articulating the epistemologies of "sameness" and "difference" that informs Hunger of Memory and This Sex Which Is Not One. Finally, this cross-reading will allow me to nuance the dichotomic tendency inherent in criticism which tends to consider Rodriguez's first book as either neoconservative or progressive and This Sex as either essentialist or anti-essentialist. Thus, if Henry Staten has convincingly argued that Hunger is situated "at the complex intersection of a both-and and a neither-nor" (104), I will argue that the complexity of this intersection, which accounts for the multiplicity of voices at play in these texts, continues to unfold if we consider the relative points of convergence and divergence between these two theoretical / literary texts and, as it were, use the two texts to unlock each other.

Rodriguez's promotion of cultural assimilation is grounded upon a dichotomic logic which sets the "private" and "public" spheres in a relation 
of mutual exclusion. His political argument seems straightforward: in order to assimilate to the hegemonic culture, ethnic minorities in the U.S. need to disavow what the author uncritically defines as their "private individualit[ies]" (26) with all they entail (i.e., native tongue, familial intimacy, cultural origins, ethnic and class bonds). This dichotomic understanding of identity formation is articulated around an image that is key to the shaping of Rodriguez's sense of selfhood in the U.S.: "[O]utside the house was public society" he writes; "inside the house was private. Just opening or closing the screen door behind me was an important experience" (16-17). For the moment suffice it to say that Rodriguez's dichotomic logic is structured around the trope of the "screen door." This image introduces a rupture, or discontinuity, between what the author perceives as two incompatible spheres: the "private" world of familial intimacy conveyed through Spanish and the "public" world of education based on English. Thus, for Richard the protagonist, the process of opening and closing the door involves an articulation of identity upon two dichotomic and contradictory poles. ${ }^{5}$ Speaking of the difficulty of coordinating two different languages Rodriguez states: "It is not healthy to hear such sounds so often" (17). According to Rodriguez's identity politics, in order to avoid a schizophrenic split, the in-between subject is forced to sacrifice the "difference" inherent in the "private" sphere for the "sameness" which characterizes what José David Saldívar has called the "homogeneity of U.S. nationalism" (Border, ix). That is to say, he/ she needs to choose between "inside" and "outside," "Spanish" and "English," "private" and "public individuality." Thus, it seems, on the surface at least, that inherent in the trope of the screen door is a fundamental "closure" to the "private" sphere, since the subject cannot sustain the psychic transition from the private to the public sphere and vice versa. "[T]he screen door shut behind me as I left for school" (39), writes Rodriguez, and since his autobiography's subtitle is The Education of Richard Rodriguez, it could be inferred that the screen door's closure is definitive ${ }^{6}$ and that a unique telos drives this narrative. Finally, it appears to follow that according to Rodriguez, no sense of (an American) identity - which he understands according to its etymological meaning, from Latin identitas, the same-can be grounded on two antithetical poles.

The image of the screen door is instrumental in articulating the fundamental "twoness" of the in-between subject in the U.S. - an aspect which both Rodriguez's political stand in favor of assimilation (i.e., Americanization) and the either/or logic that sustain his narrative fail to address. Our understanding of the logic which underlies this image might improve if we compare it to Irigaray's conceptualization of the "vagina" and the "twoness" inherent in it. Both theoretical models, in fact, share a concern with an articulation of what Irigaray calls the subject's "multitude of 'selves'" (17): 
that is, a subject which, as Irigaray's puts it, is "at least two" (26). And I consider this consideration of a subject that is "at least two" as a key point of anchorage that provisionally links these two authors across the theoretical abyss that divides them. However, before initiating a dialogic relationship between Rodriguez and Irigaray it is necessary to make a few preliminary remarks to clarify the specificity of each approach. First, Hunger of Memory is a literary text, and the theory of identity that informs it calls for a hermeneutic effort since it is not entirely explicit. This Sex Which Is Not One is a theoretical text-albeit a peculiar one since at times theory and fiction are conflated-which deals directly with a reconfiguration of female subjectivity. Second, Rodriguez deals with the articulation between the public and private spheres starting from the case of an ethnic minority in the U.S., whereas Irigaray focuses mainly (though not only) on the privacy of a solipsistic female subject. The former is mostly concerned with the category of race, class, and ethnicity; the latter focuses on sexuality and gender relations. Third, Rodriguez's autobiography is not explicitly representative (he says: "I write of one life only. My own."), whereas Irigaray's project is wider in scope and ambition since she attempts to (re)conceptualize the epistemic foundations of female subjectivity. Finally, if Rodriguez writes from within the hegemonic sphere, Irigaray situates herself at a distance from patriarchal conceptualizations of gender in order to take a critical stand towards the hegemonic culture.

More specifically, the stakes inherent in This Sex Which Is Not One, a critique of psychoanalytic discourse on female sexuality, are already implicit in the title. On the one hand, Irigaray refers to the sexist conception of female sexuality inherent in the history of psychoanalysis: Freud's postulation that female sexuality is predicated upon a fundamental lack (the notorious "penis envy") which deprives the female sexual organ from the status of being "one." Thus, according to the French critic, psychoanalysis reduces the female genital organ to less than one sex (a "zero," a "nothingness"). On the other hand, her "feminine" language shows the capacity to displace the stability of the patriarchal edifice. "You are right, our sex, is indeed not one," she seems to say, "but two, three, or better, multiple." In a subversive move Irigaray turns lack into excess. The title, moreover, reveals an excess of meaning which mirrors the plurality and slipperiness of "speaking (as) woman" (parler femme). The "two lips in continuous contact" (24) which constitute the female genitals and account for the plurality of female sexuality also account for the plurality of meanings inherent in feminine language (see 29). Irigaray's slippery language conflates genitalia and the mouth, anatomy and gender, "femaleness" and femininity. This strategic move allows her to dismantle the psychoanalytical focus on "sameness" ("one" sex) while promoting the "difference" ("at least two") inherent in female sexuality. After these rough preliminary 
remarks, suffice it to say that while being aware that Irigaray's focus is limited to the sphere of gender and sexuality, I consider the theory that sustains her understanding of the female subject to be applicable to the category of "subject" tout court. ${ }^{7}$ Further, I believe that Irigaray's critique of the "a priory value [given]to Sameness" (72) generatively intersects with Rodriguez's ambivalent relationship to the "economy of sameness" which informs his work.

After this brief and necessarily partial delineation of the specificity of Irigaray's project, it is not surprising that the radical feminist and the Hispanic writer's epistemic models of subjectivity (i.e., the vagina and the screen door), appear to be antithetical. Rodriguez's conscious political stand in favor of assimilation (the door's closure on the private sphere) makes him complicit with the dominant ideology, whereas Irigaray's resistance to an "economy of the Same" is subversive of the dominant patriarchal order. The promotion of difference and multiplicity implicit in Irigaray's theory of the subject is confirmed if we consider her understanding of the female genitalia. Woman's "genitals" she writes, "are formed of two lips in continuous contact. Thus, within herself, she is already two" (24). The image of the vagina is instrumental to promote a non-unitary vision of the subject. What follows is that Irigaray's "twoness," unlike Rodriguez's, is not predicated upon a violent division within the self which introduces a schizophrenic split, but rather on a contiguity between a "multitude of 'selves'" (17). Furthermore, her focus is on woman's "'fluid' character" (109) as well as on the "transgression and confusion of boundaries" (106) that this fluidity entails. If, on the one hand, Rodriguez seems to use the trope of the "screen door" in order to posit normative boundaries which delimit the identity of the minoritarian subject in the U.S., Irigaray, on the other hand, is concerned with the deconstruction of normative (i.e., patriarchal) limits imposed on the female subject. In brief, Irigaray's "vagina" opens up intellectual space for the constitution of subjectivity that avoids the trap of identity predicated on sameness. According to Irigaray, the "other" is in fact always already within the female self.

\section{III}

With these theoretical considerations in mind I return to Hunger of Memory. The economy of sameness inherent in Rodriguez's identity politics and his commitment to an "either/or" logic are responsible for the teleological drive which sustains Rodriguez's narrative of social progress. In the initial lines of the book we read that his educational process leads him from the status of a "'socially disadvantaged child" " to the one of "a middleclass American man. Assimilated" (3). This movement leads the subject from childhood to adulthood; from "alienation" to "assimilation"; from 
"disadvantage" to "success." In brief, from "negative" to "positive." ${ }^{8}$ As the author makes clear in the first chapter, this is "[a]n American story" (5) which depicts the realization of the "American Dream." Rodriguez's Manichean logic justifies the price to pay for "success" (45): since one cannot "become a public person while still remaining a private person" (34), the achievement of "success" implies the disavowal of the in-between subject's "private individuality" (26). Bluntly put, the destabilizing condition of "inbetweenness" structured upon the private/public binary opposition needs to be forsaken. This seems to be only a minor disadvantage since it is with pride that Rodriguez affirms: "I celebrate the day I acquired my new name" (27): "Rich-heard Road-ree-guess," the American subject, replaces "Ricardo" the Mexican subject; and, what ensues, to put it with Irigaray, is the promotion of a conception of identity predicated upon an "economy of the Same" which, in turn, sustains his stand in favor of cultural assimilation and monolingual education. ${ }^{9}$

Informed scholars of Hunger of Memory have rightly criticized the absoluteness of Rodriguez bipolar logic. Juan de Castro is to my knowledge the most recent critic (and probably not the last) who reiterates a point that had already received much attention as he denounces the "rigidity of the public/ private dichotomy" (104); and Ramón Saldívar, in a pioneering article, logically concludes that because of this rigidity, or, as he puts it, because of the "absolute separation between the private and the public" Rodriguez posits, "no dialectics develops" between these two poles ("Ideologies," 27; my emphasis). ${ }^{10}$ Both critics are right insofar as we limit our reading to Rodriguez's explicit political program. However, it should also be noted that the fallacy inherent in such categorical readings is a tendency to read literary texts in sociological and political terms without paying close attention to the contradictory undercurrents at work in the texture of the text. ${ }^{11}$ And, if we look more closely at the textual forces at work in Hunger of Memory we shall see how the "rigidity" and absoluteness of Rodriguez's binary (political) thought begins to crumble and a dialectics of identity begins to develop.

The absoluteness of Rodriguez's either/or logic is already challenged by a closer examination of the screen door, the literary trope that structures the private/public dichotomy. We have already noted that the door establishes a rigid and static polarity between the inside and the outside. This move contrasts with Irigaray's epistemic model based on continuity and fluidity and justifies de Castro and Saldívar's criticism. What these critics do not note, however, is that the subject (the protagonist), articulates its sense of selfhood by moving between the private and the public sphere (i.e., by "opening and closing the door") and, therefore, transgressing the frontier the author initially establishes. On the one hand, this movement between subject positions is reminiscent of Irigaray's discussion of "fluidity" and 
"transgression of boundaries." On the other hand, the logic that sustains Rodriguez's epistemic model is dialectical and based on a violent asymmetry of power and a radical discontinuity of experiences which is foreign to Irigaray's epistemic model (I will return to this important point).

\section{IV}

Michel de Certeau's conceptualization of the "frontier" is useful to further articulate some fundamental differences between Irigaray's and Rodriguez's theoretical models. In fact, Rodriguez's screen door operates according to a logic that is reminiscent of what de Certeau has called "the paradox of the frontier" (127). Unlike Irigaray's epistemic model which focuses on continuous contact only, the frontier has a paradoxical function because it both divides and unites. To put it with de Certeau, the frontier serves both as a "barrier" and a "bridge" since it is a place of "disjunction" and "conjunction;" "separation" and "communication" (127). ${ }^{12}$ Similarly, it can be said that the young Richard, by opening the door, introduces a continuity (conjunction) between the private and the public sphere which potentially allows for the inclusion of the public into the private and vice versa. However, as the two worlds are put in communication, he also soon realizes the incongruity and discontinuity (disjunction) existing between these two spheres. For Rodriguez, the process of opening the door, which puts the private and public sphere in contact, is simultaneous with the realization that these two worlds are incompatible (implicit in the door is neither simple "disjunction" nor simple "conjunction," neither simple "bridge" nor simple "barrier"). Moreover, the moving subject soon discovers that these two worlds are structured upon a severe asymmetry of power which makes the screen door a zone of uneasy and conflictual contact. Rodriguez's identity politics reposes on a severe clash of perspectives which confronts the absoluteness of his binary oppositions (i.e., the necessity of "separation" between private and public inherent in his political views) on the one hand, and the necessity to articulate and "open up" a space, through writing, in-between the two constitutive poles of his identity (i.e., the dialectical "communication" that finely intertwines in the texture of Hunger) on the other hand.

Rodriguez's ambivalent attitude towards his "private" and "public individuality" results in the presence of two oppositional teleologies that underscore his narrative. On the one hand, an explicit and superficial textual current displays Rodriguez's attempt to promote a vision of the subject predicated upon an "economy of the Same." This current accounts for his stand in favor of monolingual education and cultural assimilation to the hegemonic order, and it leads the subject from the private to the public sphere; from the inside to the outside. On the other hand, it should also 
be noted that Rodriguez's narrative, as the title suggests, is also grounded upon a nostalgic vision of the private sphere he disavowed. Commemorating the lost world of intimacy Rodriguez writes: "Boyhood memories beckoned, flooded my mind. (Laughing intimate voices. Bounding up the front steps of the porch. A sudden embrace inside the door.)" (71) In these lines Hunger's "counter-telos" is introduced: the subject is subjected to the "flood" of memories which, by pulling him "inside the door," runs against the grain of Rodriguez's conscious project of social upwards mobility and cultural assimilation. According to this narrative vector, his autobiography can be read as a mourning of the loss of his Mexican name, language, and cultural background. Thus, if Rodriguez's conscious promotion of Americanization takes him from the "private" to the "public" sphere and involves a closure on the latter, the hunger of memory which animates his textual project involves a return, through writing, from the "public" to the "private" world. Rodriguez tries to unlock the door he had once closed. This paradoxical double-teleology and the double narrative movement that ensues have destabilizing textual (and political) implications. First, they trouble the linearity of Rodriguez's narrative of social progress. Second, they threaten to disrupt the boundaries between inside and outside, "private" and "public," which the author consciously construes. Third, and most importantly, they challenge the unity and coherence of Rodriguez's narrative voice. Finally, it should also be noted that the disruptive dimension inherent in Hunger's ambivalent texture is not only destructive but also potentially empowering.

The double movement (from "private" to "public" and vice versa) inherent in the texture of Rodriguez's text generates aporias that the author cannot fully control and that account for the radical implications inherent this text. Rodriguez writes: "I evaded nostalgia. Tried hard to forget. But one does not forget by trying to forget. One only remembers" (50). I suggest that a similar tension is present in the narrative: a conscious political program which favors assimilation and sameness is constantly subverted by an underlying (i.e., unconscious) radical drive which restores difference to the surface. To put it in Freudian terms, Hunger of Memory can be read as the return of the repressed private sphere. The theoretical limitations inherent in sociological and political criticisms that insists on the literalness of Rodriguez's reified set of fixed polarities and promotion of assimilation is that they fail to consider what Judith Butler has called "the critical dimension of the unconscious which, reemerges within the discourse of the subject as the very impossibility of its coherence" (Gender, 28). ${ }^{13}$ In other words, they only consider one telos and listen to only one of Rodriguez's narrative voices. Namely, to the voice of Richard the protagonist who strives to achieve a new sense of individuality predicated upon public identity and signified by the Americanization of his first name 
(Rich-heard)—Rodriguez's political agenda approximates this position. The other, more dissident voice, which these critics fail to hear, is linked to Rodriguez the writer who, having ventured outside in the public world of education and having achieved the "American Dream," realizes that his is an "odd success" (44). He is forced to confront the return of the repressed private sphere signified by his Mexican name (Ricardo).

It must be noted that if Rodriguez's autobiography obviously necessitates a first person narration, the reader should be careful not to conflate the contradictory voices at play in this text under the monolithic signifier of the author's name. What is challenged in Hunger of Memory is precisely such unitary and coherent conception of the subject. To put it in Irigaray's terms, the subject of Hunger is "not identical with [him]self"" (111) (pas identique à soi), and therefore, like Irigaray's "woman," his identity is "not one." The ambivalence of Rodriguez's narrative voice testifies to it and so do the contradictory responses this text has generated (I will return to this point, see n16). In this respect, since his narrative is oriented in two opposed directions, Rodriguez's can be seen as an (at least) Janusfaced narrator who says the most contradictory things. Furthermore, Rodriguez's voice can be compared to what Irigaray's says of parler femme, which involves a "voice that overflows the 'subject'" (une voix qui déborde le "sujet") (112). Implicit in the notion of débordement (literally going over the borders) is a transgression of limits due to an excess of meaning, which very much applies to Rodriguez's transgression of the conceptual borders he initially posits. ${ }^{14}$ The first task of a rigorous reading of Hunger, it seems to me, is to disentangle this excess of meaning by identifying who is speaking at a given moment in the text and from which narrative position. More precisely, this involves tracing the text's untidy intermixture of voices and their contradictory interactions. ${ }^{15}$

The two dissonant voices I am tracing can be defined in terms of what Stuart Hall has influentially called a "struggle around positionalities" (92). That fictive unity which is Rodriguez's literary persona occupies at least two places at once. To put it in a simplistic and schematic way, Richheard the assimilationist is positioned on the "private" side of the door and dreams of the "public" side, whereas the other, more dissident Rodriguez is positioned outside the door and attempts, through writing, to unlock the door of memory in order to let Ricardo speak. ${ }^{16}$ The radical dimension of the book arises from those moments in the text where Rich-heard's conscious political program is subverted by the return of Ricardo (Irigaray's "other" within the self, see This Sex, 28). This "other" comes back to unsettle the narrative and, as Caliban would say, to claim his share in the 
"run of this isle" (3). It is to the unconscious critical dimension and to its dialectical articulation with the conscious "discourse of the subject" (i.e., Rodriguez's political agenda) that I now turn.

Hunger of Memory is predicated upon a constant transgression of the screen door that divides private and public life. Hence, despite the author's conscious attempt to construe his narrative upon an economy of sameness-assimilation functioning as a guarantor of a coherent and harmonic notion of selfhood-the subject's transgression of identity borders involves a schizophrenic rupture within both selfhood and narrative. Such a rupture is already implicit in the autobiography's very first lines: "I have taken Caliban's advice," writes Rodriguez, "I have stolen their books. I will have some run of this isle." (3). Rodriguez's reference to The Tempest allows him to play on the ambiguity upon which his own narrative and self are construed. In fact, if on the one hand Rodriguez identifies with Caliban and the subjugated position he occupies, on the other hand he establishes a relationship of continuity with the foremost authority in English literature in order to justify and insure his position within the realm of Western culture. ${ }^{17}$ The direct parallel is with a subject subjected to the hegemonic order, and yet the indirect correlation with Shakespeare puts Rodriguez in the position of mastery over language which Caliban lacks. In other words, already in these initial lines, the author introduces different possibilities for social and psychic identification so as to suggest that his relationship with the private/Mexican/subjugated side of his identity and the public/ American/dominant one is at best ambivalent. In short, he is both slave (Caliban) and master (Shakespeare) and yet, neither fully slave, nor fully master. Rodriguez's in-between position is based on a potentially destabilizing tension generated by two (ant)agonistic sites of identifications. The constitution of his literary and non-literary self involves a constant negotiation between these conflicting identificatory sites. ${ }^{18}$

The complexity inherent in Rodriguez's multiple and conflicting identifications-what Butler would call Rodriguez's "identificatory fluidity" (Bodies, 99)—unfolds as we linger more on the implications of the author's identification with Caliban, while keeping in mind the contextual bipolar logic that informs the narrative as a whole. The author makes clear that it is through language - and, more specifically, written, cultivated languagethat he assumes a position of agency. However, the medium he uses to affirm himself is not originally his, and upon this paradox pivots Hunger of Memory. The project that underscores the whole narrative is here encapsulated in a nutshell: how can Rodriguez make "their books" his own, in order not only to "have some run" of an environment which is inimical to his cultural origins, but also to gain control over the definition of himself? In other words, his identification with Caliban and the transgressive act of "stealing," implies agency and a subversion of the dominant order; and 
yet, at the same time, Rodriguez remains radically dependent on and complicit with the hegemonic values. José David Saldívar, makes this point as he says that "paradoxically, [Rodriguez] pretends to join Caliban's school of cultural resistance" while "the dominant U.S. literary public has by now legitimated his work" (Dialectics, 136). And he resolves this paradox by affirming that "Rodriguez is not a Caliban protagonist; rather, he has become, in Renato Rosaldo's words, 'an icon of collaboration with the English only movement and the conservative right wing'" (Dialectics, 137) ${ }^{19}$ This criticism is partially right insofar as we listen to the textual voice of Rich-heard the assimilationist: a docile subject who uncritically and passively swallows the canonical books of the school of Prospero (i.e., the dominant culture). However, as pointed out, the linguistic forces that traverse Hunger are far from being unilateral and allow for the simultaneous flow of contradictory movements. In brief, the text undermines an either-or logic which allows critics to easily place Rodriguez either on the side of subversion (Caliban), or on the side of the dominant, conservative order (Prospero). ${ }^{20}$

The underlying ambivalence and complexity inherent in Rodriguez's in-between subject positions unravel further as we return to the autobiography's beginning and carefully disentangle the contradictory double movement which animates it. "Once upon a time," he writes, "I was a 'socially disadvantaged' child. An enchantedly happy child. Mine was a childhood of intense family closeness. And extreme public alienation. Thirty years later I write this book as a middle-class American man. Assimilated."(3) The juxtaposition of the fairy tale-like incipit and the crudeness of social reality generate a tension which parallels the one between private and public sphere. The world of childhood, happiness, and intimacy, characteristic of the private world as well as of fairy tales, is undermined by the social (public) reality which surrounds it. Moreover, despite the fact that this is a typical "American story" (7) insofar as it depicts the climbing of the ladder of social progress and the achievement of the "American Dream" (the fairy tale come true), the structure of Rodriguez's argument undermines his dichotomizing (Manichean) tendency. In fact, the "socially 'disadvantaged"' childhood which characterizes the author's private sphere is not immediately dismissed according to a purely materialistic perspective (notice the quotation marks as a signifier of a certain degree of distance from the values characteristic of the hegemonic order). Rodriguez makes clear that his private sphere was only (if at all) materially "inferior" to his present middle-class American status. If the movement is from childhood to adulthood; from social disadvantage to middle class; it should be specified that an inversion of perspectives concerning the private and public spheres also takes place. In fact, the narrative of social progress turns "family closeness" into family alienation and "public alienation" into what could be ironically defined as "public closeness" (i.e., an oxymoron for Rodriguez). ${ }^{21}$ 
Further, the speaking subject writes from a position of otherness, or alienation, with respect to his earlier self. The temporal distance (thirty years have passed) introduces not only a gap between Rodriguez the child and Rodriguez the adult, but also between Rich-heard and Ricardo (with all the cultural implications these two names entail); the political ideologies that animate these two subjects should not too hastily be conflated. In brief, the beginning already foreshadows the schizophrenic split that the image of the screen door introduces. Behind the reassuring tone that informs Hunger of Memory's first paragraph we already sense the problematic nature of this "American hero" and, most strikingly, we begin to hear the dissident voice of a minoritarian subject that undermines the hegemonic order from within.

The clash of narrative forces inherent in this text unfolds if we consider the second chapter entitled "The Achievement of Desire." The double movement I am tracing (the two vectors that take the subject away/towards the "private" sphere), finds a condensed expression in the linguistic structure of this title. The ambivalence and slipperiness of the title is generated by the fact that, technically speaking, "of desire" is both objective and subjective genitive. Less technically, "desire" is on the one hand, what is "achieved" (objective genitive) (we will have to specify what this abstruse formulation might mean) and, on the other hand, what is responsible for the "achievement" (subjective genitive). More concretely, one way of understanding the first vector of Rodriguez's thought consists of considering Richard (Richheard) the subject, who, endowed with agency, "achieves" the object of his desire: i.e., education. Thus, throughout the chapter, speaking of the books he read, Rodriguez states: "I reported the achievement to a teacher and basked in the praise my effort earned" (61), and later he would "marvel at the breadth of [his] achievement" (63). In this perspective, what is desired (i.e., education and the assimilation to the dominant order that ensues) seems to be "achieved." This narrative movement supports the narrative of social success which takes the subject forward, towards the public sphere and parallels Rodriguez's promotion of cultural assimilation.

The linearity of this first telos is complicated if we consider that Rodriguez's "achievement" reposes upon an identificatory practice with the figures he considers as embodiments of "public" culture. He states: "I wanted to be like my teachers, possess their knowledge" (55). It should be noted that Rodriguez does not want to establish a relationship of similarity with his teachers (to be like them)-this would imply a preservation of some individual characteristics, since a relationship of similarity, rigorously speaking, involves two different terms. Instead, identification with his teachers concerns the young Rodriguez's whole sense of "being" 
(he wants "to be like" them). This identification practice strips the subject of an independent sense of selfhood and, thus, radically undermines the very possibility of agency implicit in the notion of "achievement." Rodriguez, following Richard Hoggart, calls the product of this unconditional identification the "scholarship boy": an "imitative and unoriginal pupil" (44). In other words, Rodriguez's attempt to accede to power via education corresponds to a submission to the hegemonic order which produces a passive, empty subject. The author's voice, once again, seems to allude to the most contradictory things: On the one hand, implicit in the focus on "achievement" is a notion of agency which is necessary to sustain his narrative of social progress and assimilation (i.e., his political program). On the other hand, his description of the "scholarship boy" and the tone of the chapter make clear that the author is ironic with respect to his "achievement." Finally, what is achieved is not so much education (and the successful assimilation which education makes possible) but, rather, an empty subject animated by a state of permanent lack. Put differently, what the subject seems to "achieve" is a state of unsatisfied "desire" responsible for the "hunger" that animates his writing. ${ }^{22}$

The second possible interpretation concerning the voluntarily grammatical and semantic ambivalence of this title consists in considering "desire" as the subject of the sentence and "achievement" as its object. ${ }^{23}$ According to this perspective, Rodriguez is subjected to his desire rather than being a subject who controls an intentional "achievement." More precisely, Rodriguez tells us that desire does not lead the subject forward, towards assimilation, but rather backward towards the past-a movement which is consistent with the nostalgic mood of the chapter and the autobiography as a whole. The inversion of telos is apparent if we consider the last sentence of the chapter:

It would require many years of schooling (an inevitable miseducation) in which I came to trust the silence of reading and the habit of abstracting from immediate experience . . . before I turned unafraid to desire the past, and thereby achieve what has eluded me for so long-the end of education. (73)

Rodriguez's "turn" in order to "desire the past" consists of his first step towards a subversive identification with Caliban. That is to say, he takes Caliban's advice to steal the books of the dominant culture (an active and subversive act) in order to bend the language of the colonizer to his own purpose and, thus, like Caliban, rethink possibilities of subversion within the sphere of the hegemonic order. Inherent in this subversive desire for the past is both the "end" (i.e., the conclusion) of "education" known to the scholarship boy (the end of imitation or "miseducation") and, most importantly, 
a renewed understanding of the "end" (i.e., the goal) of education: namely, the shaping of the self on and against the hegemonic sphere. ${ }^{24}$ We begin to see that the radical ambivalence of Rodriguez's use of language is isomorphous with Irigaray's parler-femme, since it allows for the construction of multiple and contradictory meanings and narrative movements. Both Richheard's desire, the scholarship boy who strives for public assimilation, and Ricardo's, the Caliban figure who turns his back on his scholastic achievement in order to "desire the past," are at work in the grammatical structure of this title (and chapter). However, as the closure of the chapter makes clear, Rodriguez, at this moment in the text, privileges the turn to the past (the opposite of the teleology which he initially proposes). The difficulty of reading Hunger consists, among other things, not only of identifying who is speaking (with whom does Rodriguez identify at a particular moment in the text ${ }^{25}$ but also of assessing the value and strength of this voice within its proper textual economy. In this light I suggest that this second chapter functions as a turning point where a "forward looking" desire turns into a past-oriented desire. The chapter comes thus to occupy an in-between position within Hunger's textual economy as a whole: it functions as a crossroad where two vectors of desire diverge radically. This may account partially for the semantic ambivalence of the title which approximates Irigaray's definition of parler femme.

\section{VII}

If on the one hand Irigaray's considerations of subjectivity are instrumental to tease out the multi-layered and polyphonic dimension of Hunger, on the other hand, Irigaray's radicalism can in turn be nuanced in the light of the more subversive forces at work in Rodriguez's text. It should first be noted that the French theorist's focus on the female body has predictably led to what Margaret Whitford calls a "monolithic essentialist reading of Irigaray" (16). Monique Plaza, one of the first to attack Irigaray on this ground, sums up the argument as she states that for the French radical feminist "the potential existence of woman thus depends on the discovery of her essence, which lies in the specificity of her body" (quoted in Schor, 6). ${ }^{26}$ What concerns me here is not so much the fact that Irigaray chooses to ground her epistemic model of the subject on the female genital organ, but rather the theoretical implications inherent in her epistemic model, and its functioning within its proper textual economy. ${ }^{27}$ Let us first notice that, for Irigaray, the focus of attention is "not so much the anatomy but ... the morphology of the female sex" (qtd. in Burke 51). In other words, what matters, for the French philosopher, is the form or shape (Greek, morphé) of her bodily schema, and not the fact that it is an anatomical model. And it is with this theoretical warning in mind that I turn to (re)consider her epistemic model of subjectivity. 
Implicit in the "morphology" of Irigaray's schema, is a conscious evasion of the violence and contradictions which sustain dialectical thought. In fact, Irigaray's "vulvomorphic logic" (Gallop, 95) neither postulates a hierarchy between its constitutive poles, nor necessitates the presence of (sexual) "otherness" outside the (feminine) self. Thus understood, the feminine subject does not stem from a generative tension between self and other; inside and outside; subaltern subject and cultural hegemony. ${ }^{28}$ Put differently, the vaginal schema suggests that Irigaray's concern with the subject takes place at the level of intra-subjectivity and does not address the problem of inter-subjectivity. Since the other is "always already" within the self, Irigaray does not need to articulate a space for the encountering of others outside the self, in the wider social sphere..$^{29}$ In fact, negotiation of identity, for the French feminist, takes place within the private dimension of a kind of autoerotic desire that is highly suspicious of sexual difference. ${ }^{30}$

Moreover, despite Irigaray's claim that woman "is kept from dispersion because the other is already within her" (31), the "morphology" of Irigaray's epistemic model suggests that the contact between the two lips is not a contact with otherness but rather a symmetrical contact with an other that is the same. The articulation of what she calls a "multitude of 'selves'" is not generated by an asymmetrical tension with otherness (and the pain it involves) but rather by a pleasurable contiguity with sameness. Irigaray, thus, speaks of a pleasurable "contact" predicated upon a "nonsuture of [the] lips" (30) which guarantees a space for the affirmation of "the other in herself" (28). If on the one hand Irigaray's epistemic model promotes contact and continuity of identities, on the other hand what guarantees this continuity is a closure to and discontinuity with the cultural hegemony. Or, to put it in de Certeau's terms, the "vagina" initially appears to function as a bridge that connects. However, this bridge connects the subject with itself (i.e., with a "sameness" which is inside the feminine subject) rather than with "difference" outside the self. Further, the morphology of the "vagina" also suggests that this model functions as a frontier or boundary that divides sexual "sameness" from sexual "otherness" by establishing the absoluteness of the gender/sexual divide. ${ }^{31}$ Rosi Braidotti, in her overall positive assessment of Irigaray, puts it even more crudely as she writes that "Irigaray ends up upholding" the "metaphysics of the sexual dichotomy masculine feminine" (56). For our purpose, suffice it to say that implicit in the radical feminist's theoretical model of subjectivity is a disavowal of the necessity of a severe confrontation with the hegemonic, phallocentric order. ${ }^{32}$

The two lips which guarantee the "multiplicity of female desire" (30) as well as the "multitude of "selves"" which constitute "woman" are kept from dispersion insofar as they are rooted in the unity implicit in the morphé of Irigaray's epistemic model. Irigaray seems to involuntarily articulate 
the theoretical implications of her model in her retelling of Carroll's Alice in Wonderland, "The Looking Glass, from the Other Side," which functions as the first chapter of This Sex Which Is Not One:

This story is coming to its end. Turning and returning in a closed space, an enclosure that is not to be violated, at least not while the story unfolds [Se tournant, et retournant, dans une enceinte qui ne sera pas transgressée, du moins pendant son déroulement]: the space of a few private properties. We are not going to cross a certain boundary line ... We have never been dealing with more than one, after all. A unity divided in halves.

This statement seems to match Irigaray's conception of the vagina (i.e., of the subject): an impenetrable entity which is constituted in a "closed," "private" space which ultimately can be defined as a "unity divided in halves." 33 In other words, despite the focus on multiplicity and difference, Irigaray's textual unconscious seems to suggest that the model of the vagina does not allow her to deal "with more than one." Furthermore, crossing "a certain boundary line," as Rodriguez does, implies a confrontation with difference and a necessary articulation of the boundaries of selfhood. This process, for Rodriguez, is not as pleasurable as it is for Irigaray because of the violence implicit in this crossing (in this sense Rodriguez's image of the screen door is closer to Gloria Anzaldua's conceptualization of la frontera in terms of "barbwire"). Finally, despite Irigaray's denouncement of both sameness and the Spaltung of the subject (two fundamental psychoanalytical pillars which also inform Rodriguez's understanding of identity) she seems to be unable to totally renounce these epistemic premises.

Despite my critique of Irigaray I want to stress that my task here is not to adjudicate between the Hispanic writer and the French theorist's exemplary positions, but to try to understand and acknowledge the ambivalent texture that underscores these texts in order to account for their contradictory reception. And since Irigaray affirms the necessity to "pay attention to the way the unconscious works in each philosophy" (75) I apply a "hermeneutic of suspicion" (Ricoeur's term) to both Rodriguez's text and Irigaray's own philosophy. What I find is that Irigaray's textual unconscious seems conservative if we compare it to the subversive textual dimension which animates Hunger. More precisely, Rodriguez's textual unconscious is subversive of the economy of sameness he consciously sets forth to promote, whereas behind the radicalism of Irigaray's conscious political and philosophical radical agenda is an "unconscious" that, at certain textual moments, gestures towards an "economy of the Same" and, therefore, "operates" according to the logic she sets forth to criticize.

And yet, in order to do justice to Irigaray's thought it should also be noted that despite the theoretical implications inherent in her model of the 
female subject and in her textual unconscious, Irigaray does not, a priori, preclude the possibility of a dialogue with sexual otherness. In fact, in an interview which functions as a chapter in This Sex she says: "Speaking (as) woman [parler-femme] would, among other things, permit women to speak to men"(136). However, in order for the possibility of parler-femme to develop, the female subject needs to bracket itself off from the "economy of Sameness" that, according to her, informs the hegemonic phallocentric order tout court. And it is on this key point that Rodriguez's understanding of the "twoness" of the subject, and Irigaray's, fundamentally diverge. According to Irigaray, the development of a dissident voice needs to grow on a soil that has not been contaminated by the dominant discourse. She justifies the "'breaking away' of women-among-themselves" as "strategically necessary" (tactiquemet nécessaire) (160-61). Hence, she suspends the possibility of a dialogue with sexual otherness until the female subject has constituted itself outside of the cultural hegemony. What follows is that (female) subjectivity, thus understood, is not constituted dialectically. In fact, she says that "[r]ather than maintaining the masculine-feminine opposition, it would be appropriate to seek a nonhierarchical articulation of that difference in language" (162). According to Irigaray, it is in language that her utopia (literally, no place) can be produced, where difference can be articulated outside of hierarchical and dialectical binary oppositions. In this respect she remains true to her epistemic model, insofar as her emphasis on the two lips conflates the female genitalia and the mouth; body and language. ${ }^{34}$ This conflation, she seems to imply, is a necessary condition for the development of a kind of other, multi-layered, and ambivalent speech (parler femme) which attempts to transcend dialectical thought.

\section{VIII}

Unlike This Sex, Hunger is structured upon a severe dialectical struggle where the subaltern side of Rodriguez's identity (Caliban the "slave") functions as the negative pole upon which the "success" of the American "master" is construed. In fact, it is because Rodriguez "cannot afford to admire his parents" (49) that he is forced into a relationship of identification with his teachers (the masquerade inherent in the scholarship boy). Academic and social "success" is predicated upon a violent disavowal or repression which is both personal and cultural. Speaking of his last name Rodriguez writes: "The name I carry from my parents-who are no longer my parents, in a cultural sense" (4). Rodriguez's alienation from his parents involves his cultural affiliation to the realm of Western culture (his cultural father is no longer Caliban but Shakespeare). However, if this identity shift is represented by the Americanization of his first name (Rich-heard), he cannot discard his parental last name (Rodriguez) 
and its cultural significance ("Caliban" and "Shakespeare" coexist in one subject). Further, the repressed returns to haunt both the subject's dreams of "success" and, more importantly, the hegemonic culture as a whole which created the necessity of repression in the first place. Hence the revolutionary force inherent in this text, which, in Hegelian terms, could be defined as a linguistic Kampf auf Leben und Tod between private and public sphere; slave and master; Caliban and Shakespeare.

The radical implications inherent in Hunger of Memory arise from its hero's inability to resolve the fundamental psychic, cultural, and political Spaltung that informs his sense of what Irigaray would define as an identity "which is not one." In fact, despite Rodriguez's conscious articulation of an either / or logic which requires the disavowal of the "private personality," his autobiography depicts a subject which is simultaneously both American and Chicano and yet neither fully American (whatever that may be) nor fully Chicano. ${ }^{35}$ This state of suspension between what Rodriguez perceives as two metaphysical alternatives (inside vs. outside) contributes to create what he calls "a comic victim of two cultures" (5). On the one hand, Rodriguez can be seen as a "victim" insofar as his cultural origins are found at the intersection of two poles, which, unlike Irigaray's lips, generate a state of violent asymmetrical tension and, despite Rodriguez's emphasis on comedy, tear the subject apart. Thus, the dialectics of identity at work in Rodriguez's autobiography does not involve a definitive synthesis in which both poles can be successfully and harmoniously integrated and reconciled into a coherent and unitary sense of identity (i.e., an identity that is "the same"). On the other hand, Rodriguez cannot be read as a passive victim only, insofar as he attempts, through writing, to open up an alternative space in-between the two dichotomic alternatives he initially posits. In this sense, the double-movement that animates Hunger can neither be read as an uncritical celebration of cultural assimilation only, nor as a nostalgic search for origins only, but rather as an attempt to creatively articulate these two epistemological alternatives. The result is not a harmonious resolution of the conflict of identity but a state of creative and painful suspension. It is thus significant that the autobiography's closure is also not really one since no resolution occurs: Rodriguez, in the last pages of Hunger, finds himself neither fully outside, nor fully inside the house (the door neither fully open nor totally closed) but rather on the threshold, caught up in-between the two spheres he initially so rigidly posited. In brief, at the end of the his first book he places himself precisely at that intermediate in-between position which in later writings he will come to embrace and celebrate. ${ }^{36}$

Rodriguez's tendency to fall back onto an economy of sameness (i.e., his critique of bilingual education and promotion of Americanization) can now be (re)read as an attempt to counter the more revolutionary forces 
at work in the text. These forces constantly displace the subject from a position of ("public") stability and threaten to disrupt the coherence and unity of his sense of "public individuality." Furthermore, Rodriguez's promotion of monolingualism does not concern only him as a subject, but also mirrors a national unease in dealing with the slipperiness and instability which characterizes in-between subjectivities. Rodriguez's critique of bilingual education reveals the complexity inherent in both his and the bilingualists' identity politics. Notice that his critique of bilingualists is counterintuitive insofar as he points out their inability to adequately engage with the problem of "inbetweenness" and the unstable cultural position that pertains to it. He writes: "Perhaps because I am marked by indelible color they [white American bilingualists] easily suppose that I am unchanged by social mobility, that I can claim unbroken ties with my past" (5). Rodriguez's theoretical move is subtle: he relegates advocators of bilingual education to an epistemology of sameness based on a kind of ethnic, or even worse, racial essentialism which freezes the in-between subject within the restrictive confines of his cultural origins signified by his skin color. Rodriguez dispels the exotic connotation which his origins may have: "Aztec ruins hold no special interest for me" (5). He claims that his cultural (Mexican) origins do not provide a solid ground for the establishment of his identity borders and, thus, moves away from a purist notion of racial and ethnic authenticity. ${ }^{37}$

And yet, if on the one hand, Rodriguez accuses his political opponents of proposing the "possibility" of the existence of "unbroken ties" with his past, on the other hand, he seems to fall into the same trap by going too far in the opposite direction in affirming the univocal aspect of his new cultural origins: he uncritically considers his autobiography an "American story" (5). ${ }^{38}$ The centripetal forces inherent in this claim of a unitary origin (i.e., the vector that takes the subject away from the private sphere) are also responsible for Rodriguez's (mis)understanding of bilingual education. He writes: "It is not possible for a child-any child-ever to use his family's language in school" (12). The force of his argument seems irrefutable. In fact, Rodriguez's claim is not limited to bilingual children (he addresses "any child"). However, by broadening the scope of his critique he reveals the epistemic bias upon which his political argument is predicated. In fact, Rodriguez's argumentative force stems from a rhetorical (rather than conceptual) move which deftly conflates language and language use. The difference is key. In fact, if anglophone children entering the sphere of education need to operate a shift from "private" to "public" English (a shift within two different uses of the same language), there is no reason to believe that the very same shift cannot be operated by bilingual children concerning two languages. In Rodriguez's case, the Spanish spoken at home would necessarily be different from the Spanish spoken at 
school; and yet it would still be Spanish. The mastery of the native tongue would in turn allow the in-between subject to access not only the private sphere of family relationship (Rodriguez could thus speak to his grandmother and would have a word to address his father, i.e., papà), but also the wider culture to which these relationships are linked. In brief, bilingual education would give the in-between subject the possibility of addressing her/ his private individuality (one of the "two cultures" Rodriguez speaks of) from the perspective of meaning rather than feeling only ${ }^{39}$ Put differently, mastery of two linguistic codes would facilitate the in-between subject's confrontation with the ambivalence of her/his identity. Starting from an egalitarian position (a mastery of two codes) seems a necessary condition for a reduction of the violent hierarchy between private and public and for the ability to operate what Irigaray would call, having Alice in mind, a "playful crossing" (77) between two different worlds.

\section{IX}

Rodriguez's difficulty in consciously elaborating on a language to address his cultural "twoness," mirrors not only an individual problem as his affirmation, "I write of one life only. My own" (7) might suggest, but also a wider, national uneasiness with "inbetweenness." In fact, as I have noted, Rodriguez functions not so much as a subject who is in control of his sense of identity, but rather, as one who is subjected to wider sociopolitical forces. The narrative has nonetheless radical implications since, in depicting the contradictions inherent in one specific American subject, the economy of sameness inherent in American identity politics (one nation, one language, one God) is exposed. Rodriguez, unlike Irigaray, challenges the epistemic and political privilege of sameness from within the hegemonic order; moreover, he does so by embracing a dialectical logic and by speaking from both the position of "master" and "slave" (though only through the linguistic code of the master). The politically disruptive nature of his narrative arises from the generative tension inherent in both his torn psyche and body and in its textual articulation. In fact, the double tension inherent in Rodriguez's Hunger of Memory deconstructs his conscious subscription to an "economy of Sameness" (included in his critique of bilingualism). More precisely, the process of conscious construction and unconscious deconstruction initiates a syncopated movement that threatens to disrupt the epistemology of sameness that grounds both Rodriguez's sense of "private" and "public identity." Further, this destabilizing, unresolved, back and forth movement challenges the unitary conceptions of personal and national identity. Rodriguez's involuntary radicalism stems from the in-between space opened up by this contradictory movement. 
Unlike Irigaray's conception of the "vagina," Rodriguez's image of the "screen door" is articulated upon two poles that create a state of generative "tension." On the one hand, the presence of a "tension" can be read as the actual proof that an articulation between self and other; sameness and difference is taking place. And in this sense, Rodriguez's dialectics of identity appears to be closer to the painful social reality implicit in the condition of in-betweenness. However, by discarding the possibility of an articulation between self (inside) and an other (outside), Irigaray avoids the fallacy of violence implicit in dialectical thinking, and opens up an alternative space for the articulation of female subjectivity in language. This concern with a different use of language, and the plurality of voices that are allowed to speak through it, I have attempted to show, can serve as a provisional link between Irigaray and Rodriguez's concern with a subject that is always "at least two." In fact, despite the two authors' apparent endorsement of two conflicting "economies," with respect to language use they both seem to promote a kind of writing which allows for the expression of different and contradictory voices. Disentangling them is already a literary effort with political implications in itself.

\section{University of Washington}

Seattle, Washington

\section{NOTES}

1. In Border Matters José David Saldívar, after positively assessing Days of Obligations in terms of an "autoethnographic borderland 'text" (12) goes on to point out that Rodriguez's second book "is everything that Hunger of Memory was not" (146) and speaks of a "sea change in Rodriguez's worldview" (146); see also 144, 146-47, 151. De Castro, in a similar spirit, affirms that Rodriguez, in one of the essays that would later appear in Brown, has "evolved towards a celebration of hybridity" (116) which involves a "going beyond the binary opposition that characterized Hunger of Memory" (119). Within the scope of this essay I cannot fully address the question of the continuity/discontinuity of Rodriguez's work, since that would imply a careful consideration of his three autobiographical essays. I do, however, begin to sketch a genealogy of his concern with "hybridity."

2. For a representative sampling of other critics who implicitly or explicitly acknowledge the conceptual/theoretical value of Hunger of Memory, see Randy A. Rodríguez, 398; Norma Alarcón, 150; Henry Staten, 104; and Gustavo Peréz Firmat, 258. These insightful readings, however, are not primarily concerned with the promotion of Rodriguez as a "theorist," which I take to be my focus.

3. Whitford also recognizes that "greater attention is now being paid to the status of Irigaray's writing as text, that is to say, writing that employs rhetorical devices and strategies." (16) In what follows I pay attention to both the explicit theoretical/conceptual import of the two texts under consideration and to their literary "devices and strategies." 
4. For a detailed account of the reception of Rodriguez's work until 1998, see Randy A. Rodríguez, n6, 412; n7, 413-14; for an informed delineation of the historical resonance of this debate and its relationship with chicanismo, see Henry Staten, 104-08. I will return to the question of Irigaray's essentialism below. Since both Hunger and This Sex have elicited strikingly oppositional readings, I hope their cross-reading will contribute to an at least partial clarification of the ambivalence inherent in the texture of these texts which, in turn, can begin to account for their ambivalent receptions.

5. Mimi Sheller and John Urry's excellent sociological discussion of the "private/ public" divide emphasizes the multi-layered and complex dimensions inherent in this binary. Moreover, they point out that "there is a tendency in existing literature to think in terms of [private and public] 'spheres' or 'spaces,' concepts that are often static and 'regional' in character," and they add: "We criticize such static conceptions and emphasize the increasing fluidity in terms of where (or when) moments of publicity and privacy occur" (108). It should be noted that in this essay I do refer to the "private/public" distinction since it is at the heart of Rodriguez's argument. However, my references to the "public" and "private sphere" should always be taken, as it were, in intonational quotation marks. In fact, as it will progressively become clear, I do not intend to posit a metaphysical barrier between the two worlds - a gesture which would naïvely replicate Rodriguez's political move (Tomás Rivera's reading of Hunger is representative of such criticism; see his metaphysical equations: $s e r=$ private and estar = public). Instead I set forth to show how these two "spheres" interpenetrate each other with respect to specific cultural aspects which are determined by the narrative, such as language, education, and family bondage. In other words, my focus is on the mobility of the subject and the way it undermines the stability of this binary. With respect to the inside/outside binary, my approach is most clearly formulated by Diana Fuss: “The figure inside/ outside" she writes "cannot be easily or ever finally dispensed with; it can only be worked on and worked over-itself turned inside out to expose its critical operations and interior machinery" (Fuss, "Inside/Out," 1; my emphasis).

6. In an insightful essay, Gustavo Pérez Firmat also focuses on the trope of the screen door and comes to this conclusion: "Rodriguez imagines [the screen door] as a protective barrier-opaque rather than transparent, occlusive rather than permeable" (260). Subsequently, Firmat contrasts Rodriguez's screen door to the "sliding-glass-door" of Californian middle-class families (see Hunger, 179) which, according to him "connects" rather than "isolates" (Firmat, 261). While I sympathize with this reading, I consider Rodriguez's "screen-door" less impermeable than Firmat wants it to be (see below).

7. José Esteban Muñoz points out that "[c]ultural studies of race, class, gender, and sexuality are highly segregated" (8). And cultural critic Jonathan Dollimore adds that "[t]heories of sexual difference notoriously disregard the erotics of other kinds of difference" ("Desire," 17). My intersectional reading is a modest attempt to trouble the rigidity of theoretical disciplines while, at the same time, delineating the specificity of each theoretical approach.

8. Here I exploit the moral connotation of these terms. Below I begin to consider their dialectical implications.

9. Early critics of Hunger of Memory linger at length on the (neo)conservative dimension of Rodriguez's political views and his uncritical adoption of the values 
of dominant culture which they take to be inherent in his celebration of assimilation and monolingual education for minorities in the U.S. For a representative sampling of this criticism, see Rivera, 7-10; Romero, 96; R. Saldívar, 1985:26; Flores, 86; J. D. Saldívar.

10. R. Saldívar restates the same point as he speaks of "Rodriguez's undialectical opposition between self and society" ("Ideologies," 33).

11. This theoretical tendency has been severely denounced by Rodriguez in an interview: "I think that it is the worst example of the politicization of ethnic literature, now that it is read more as sociology. Sociology is not literature" "Violating," 429-30). In his last book, Brown, he restates the same point: "The liberal-hearted who run the newspapers and the university English departments and organize the bookstores have turned literature into well-meaning sociology" (Brown, 39). It should be noted that Rodriguez's autobiographies are obviously political and seem to ask for a sociopolitical reading. However, the political implications inherent in his work, Rodriguez seems to suggest, need to be uncovered via a hermeneutic effort.

12. De Certeau adds that the frontier is "created by contacts" since "the points of differentiation between two bodies are also their common point" (127). This accounts for the paradoxical fact that the frontier, like the door, is a site of both opposition and proximity. In fact, as Jonathan Dollimore remarks, "[t]o be against (opposed to) is also to be against (close up, in proximity to) or, in other words, up against" (qtd. in Uebel, 8).

13. In this instance Butler speaks of the subversive potential of the unconscious as "a site of repressed sexuality" (28). However, as she makes especially clear in her later works, the disruptive power of the unconscious should not be understood exclusively in sexual (i.e., Freudian) terms.

14. Irigaray's additional comments on parler-femme also seem to apply to Rodriguez: "Woman" she writes, "never speaks the same way. What she emits is flowing, fluctuating. Blurring" (112). We shall return below to some specific instance of what I consider to be Rodriguez's "parler-femme."

15. I am indebted to Henry Staten's deconstruction of Nietzsche (see Nietzsche's Voice) for my approach to Hunger of Memory.

16. I hasten to add that the extent to which Rodriguez's writing is a conscious and controlled act of subversion and the extent to which his "unconscious speaks" (ça parle) is a question that I cannot address. Moreover, I'd like to make clear that I am painfully aware that my reading does not do justice to the complexity of the text, since there are indeed more than two voices speaking in Hunger, as Rodriguez's paradoxical definition of himself as a "queer Catholic Indian Spaniard" already implies (Brown, 35). I recur to this (over)simplification because it allows me to begin to address the contradictory political reactions this text has elicited. R. Saldívar explains this fundamental paradox as he states that Rodriguez "chooses to market his existential anguish to the most receptive audience imaginable: the right-wing establishment and the liberal academic intelligentsia" (Chicano, 158). Saldívar chooses to explain the textual ambivalence in purely economic terms. The text, thus understood, is a commodity among others produced in order to appeal to the maximum number of consumers (Randy A. Rodríguez, in an extensive endnote, has convincingly shown the weakness of this reading, see n.6, 412). On the other hand, I propose to inverse Saldívar's causal model. In fact, I 
consider the multiplicity of contradictory voices at work in Hunger as an expression of Rodriguez's complex social and psychic organization. To put it even more clearly, the reception of the book is mixed because Rodriguez has mixed feelings; and Rodriguez has mixed feelings because he is subjected to (rather than subject of) contradictory ideological and emotional forces. R. Saldívar, on the one hand, is deeply aware that "Chicano narrative," as he puts it, "attempts to reveal the ideological structures by which we continue to create the world" (Chicano, 9). And yet, he fails to apply his theoretical insights to his reading of Hunger. Speaking of the shame he feels for his parents and the guilt that ensues Rodriguez says: "I felt such contradictory feelings. (There is no simple roadmap to the heart of the scholarship boy)." What is true for the subject is true for the text. Rodriguez's complex social and psychic organization is the product of the oppositional ideological pressures that are exerted on him as an in-between subject and which he attempts to give shape to and map through writing (hence the two contradictory teleologies I am tracing). It should be noted that Rodriguez's textual voices cannot easily be disentangled and, therefore, there is "no simple roadmap" which indicates those moments in the texts where a severe dialectics takes place.

17. Rodriguez's strategic use of the trope of the "middle class pastoral," which he adopts in the prologue to frame his narrative, might be seen as serving a similar function.

18. Identification, as psychoanalysis teaches us, is key for the formation of subjectivity. In fact, Laplanche and Pontalis, following Freud, affirm that "[i]t is by means of a series of identifications that the personality is constituted and specified" (qtd. in Muñoz, 7). The question of identification has recently been taken up again by gender theorists such as Diana Fuss and Judith Butler. Fuss writes that "multiple identifications within the same subject can compete with each other, producing further conflicts to be managed ... The history of the subject is therefore one of perpetual psychic conflict." (Identification, 49; see also Butler, Bodies, 99). Their focus on the (ant)agonistic and contestatory dimension of identificatory practices finds a concrete literary expression in Hunger.

19. J. D. Saldívar is not alone to puzzle over Rodriguez's identification with Caliban. Gustavo Pérez Firmat also states that "[a]fter all, Rodriguez does not feel enslaved [as Caliban] but liberated by assimilation into North American culture" (257). Firmat, in this instance, rushes over the complexity of the Rodriguez-Caliban identification. In fact, like Saldívar, he uncritically listens to Rodriguez identity politics only, where "assimilation" and "liberation" are conflated and, thus, he fails to fully grasp the relevance of these initial lines. In fact, Caliban is not only a figure of "enslavement," as Firmat seems to imply, but also of potential liberation (i.e., a liberation which has nothing to do with "assimilation," but rather with the recuperation of memories). I suggest that "enslavement" and "liberation" are not necessarily contradictory terms for Rodriguez but rather correspond to different moments in the progression of his psycho-textual dialectic.

20. Critics who, in their assessment of Hunger, rely on the absoluteness of the either-or dichotomy (either Caliban or Prospero) and who categorically affirm, as R. Saldívar does, that Rodriguez "must irrevocably choose between [the private and the public], [a]nd he does choose [i.e., the public]" ("Ideologies," 27), remain trapped in the very bipolar logic they are denouncing. 
21. Renny Christopher considers the "sense of loss that haunts upward mobility" (80) in Hunger of Memory as a paradigmatic case of a type of literature which he defines as "unhappy narratives of upward mobility" (80).

22. It is interesting to note that Rodriguez's definition of the scholarship boy in terms of imitation parallels Irigaray's discussion of what she calls "masquerade." Subjects who find themselves "in masquerades" writes Irigaray, "are imported into another economy, where they are completely unable to find themselves. . . . In the masquerade, they submit to the dominant economy of desire in an attempt to remain 'on the market' in spite of everything" (133). Both Rodriguez and Irigaray denounce this docile position. Furthermore, the scholarship boy's desire to assimilate to the hegemonic order is highly reminiscent of Rodriguez's political argument in favor of assimilation; a parallel which discredits Rodriguez's political agenda.

23. Notice Rodriguez's recurrent use of the ambivalent genitive structure ("of desire," "of education"). This ambivalent formulation where subject and object cannot be easily distinguished is instrumental to generate an excess of contradictory meanings. Further, this ambivalent use of language openly etiolates the rigidity of Rodriguez's explicit dichotomic logic. It is, thus, interesting to note that this linguistic structure appears again in the subtitle of Rodriguez's last book, Brown. The Last Discovery of America, which has been praised for "going beyond the binary oppositions that characterized Hunger of Memory" (de Castro, 119). Rodriguez's ambivalent language in his first book already suggests that the binary oppositions are less stable than they first appear to be.

24. Jonathan Dollimore's discussion of the ambivalence of desire perfectly matches the conflicts of desires at stake in both this chapter and in the text as a whole. "Desire," writes Dollimore, "is always desire for something which is not yet; in that sense it is forward-looking, addressed to the future. But desire is also about the past and memory, and in that sense it is about going back" (Sex, 36).

25. With respect to identification, Diana Fuss writes: "We can thus economically summarize the difference between identifications as the difference between an active and a passive relation to the Other: to seize the Other, or to be seized by the Other" (Identification, 41). This fundamental distinction is useful to differentiate between Richard's passive relation to education and Caliban's active appropriation of the past.

26. For an informed article which traces the genealogy of Irigaray's reception within the frame of the essentialist/ antiessentialist debate, see Schor.

27. I am in agreement with Judith Butler as she defines Irigaray's "biological essentialism" in terms of a "rhetorical strategy" ("Bodies," 151). My concern is thus to understand the functioning of Irigaray's strategic essentialism.

28. Rosi Bardotti also stresses the non-dialectical dimension inherent in Irigaray's theory of femininity: "Sexual difference as a political practice," she writes, "is constructed in a non-Hegelian framework whereby identity is not postulated in dialectical opposition to a necessarily devalorized other" (46). In other words, Irigaray's break with dialectics is necessary to promote a vision of sexual difference on a non-hierarchical framework.

29. Monique Plaza makes a similar point as she states that according to Irigaray, the "feminine essence of woman can only be discovered outside of the oppressive social framework, that is to say, in the body of the woman" (qtd. in Schor, 6). 
While agreeing on the non-dialectical aspect of Irigaray's model, I think that Plaza justifies her charge of essentialism by focusing on the "anatomy" rather than the "morphology" of Irigaray's epistemic model and, thus, simplifies the question of Irigaray's essentialism. Irigaray's use of the signifier "woman" and of the thirdperson feminine singular pronoun "she" has also predictably led to an accusation of essentialism. While my assessment of Irigaray leads to analogous conclusions, I differentiate myself from this anti-essentialist criticism by not limiting my critique of Irigaray to her reference to a bodily schema and to monolithic signifiers such as "woman" or "she."

30. She writes: "This autoeroticism is disrupted by a violent break-in: the brutal separation of the two lips by a violating penis, an intrusion that distracts and deflects the woman from this self-caressing she needs if she is not to incur the disappearance of her own pleasure in sexual relations" (24). The contact with sexual otherness, according to Irigaray, is necessarily violent and disruptive. Implicit in these lines is not only a refusal to engage in a dialogic relationship with the patriarchal order outside the self, but also a fundamental closure to (sexual) difference and otherness which runs counter to Irigaray's conscious promotion of an economy of difference. The promotion of a multiplicity of selves takes place, to put it with Rodriguez, within the private sphere only. If Rodriguez initially tries to find a sense of selfhood on the public side of the screen door, Irigaray finds refuge on its private side. Implicit in her argument is an uneasiness to explore the "inbetweenness" of identity that is reminiscent of Rodriguez's identity politics.

31. It is worth noting that this notion of limit or boundary, is already implicit in the etymology of the term "morphology." In fact, as Heidegger reminds us, the Greek morphé corresponds to "the enclosing limit and boundary, what brings and stations a being into that which it is, so that it stands in itself: its configuration" (qtd. in Staten, 1990, n.8, 130). Irigaray, the student of Greek philosophy, must have been aware of the etymology of the word, and it is therefore not surprising that her epistemic model of the vagina, understood according to its morphé, operates in isolation from an outside and promotes a conception of subjectivity that "stands in itself."

32. I hasten to add that I do not mean to imply that Irigaray's work as a whole does not confront the patriarchal order. Nothing could be farther from the truth as most chapters of This Sex and her other major philosophical work, Speculum Of The Other Woman, make clear. My point is limited to the theoretical conclusions which can be drawn from her epistemic model of the female subject.

33. Notice that the English word "enclosure" lacks the ambivalence inherent in the French term "enceinte" which also signifies pregnancy. Thus, in the original, the link to the female body that must not be "violated" during pregnancy is more explicit (see also the reference to "tournant and returnant" as a possible allusion to the movement of a baby in the maternal womb). I will return to this ambivalent passage below, see n. 35 .

34. In this light, Irigaray's aforementioned quote ("This story is coming to its end. Turning and returning in a closed space, an enclosure that is not to be violated, at least not while the story unfolds ... ") acquires another significance. Irigaray's reference to a "closed space" which is also "a unity divided in halves" seems not only to allude to the privacy of the female genital organ but also to the morphology of the book, and 
most importantly, to the "private" act of writing. Inherent in this second reading of this ambivalent passage is a disruption of the "boundary line" that divides "private" from "public" sphere; a move which strikingly approximates Rodriguez's understanding of writing as a lonely practice which is also, as he puts it, "the most public thing [he has] ever done" (176). In this respect, both writers seem to share a belief in written languages as a site of articulation for new possibilities of subjectivity. And yet their textual logic cannot be too easily conflated.

35. Henry Staten makes a similar point as he writes that "Rodriguez's acute awareness of the ironies of such cultural location (both-and, neither-nor) motivates his refusal to count himself as a Chicano" (113). Irigaray's definition of woman also seems to approximate Rodriguez's psychic condition: "She is neither one nor two," she writes, "rigorously speaking, she cannot be identified either as one person, or as two" (26).

36. I am here in disagreement with R. Saldívar who reads Hunger's last lines in terms of a definitive closure and resolution. Saldívar reads Rodriguez as a Christlike figure "leaving the last supper of familial discontent ready to be reborn as the published autobiographer of assimilated middle-class Mexican America" ("Ideologies," 28). The fact that Rodriguez is the last of his brothers to live, the nostalgia that permeates this ending, and the in-between position which he occupies at the closure of the text are all textual elements which indicate Rodriguez's incredible reluctance to move towards "assimilation." Furthermore, his subsequent works pick up from where he was left at the end of Hunger, and show that there is no escape (no Christ-like rebirth) from the in-between position he occupies. Thus, especially in Brown, Rodriguez comes to embrace this in-between, suspended, position by "celebrat[ing] the browning of America" (xiii). Retrospectively, it can provisionally be said that the disruption of a unitary vision of the subject which takes place in Hunger serves as a necessary step for Rodriguez's subsequent celebration of inbetweenness and "hybridity."

37. It is interesting to note that in Brown, despite his celebration of hybridity, Rodriguez retains his promotion of English language for minorities in the U.S. while, at the same time, giving to his argument a new subversive spin. In fact, in his last book, Rodriguez strengthens his identification with Caliban (and the cannibalism that is associated with this figure) since he sees in the "omnivorous appetite" of American English a de-territorializing force which is cogent with the "hybridity" (i.e., "browning") he is promoting. His theoretical move is, once again, counterintuitive. In fact, according to Rodriguez, the devouring force inherent in American English does not imply a reduction of difference (minorities) to sameness (cultural hegemony), as advocators of bilingual education would claim, but its very opposite instead. While this account fails to convince me, it is worth noting that Rodriguez posits difference at the origins of American English. This involves a revision of the genealogy of the hegemonic language in the U.S. Namely, as he had already hinted at in Hunger (see 33), he posits the "African slaves stealing the language, learning to read against the law" as the transforming agents of "English language into the American tongue" (Brown, 31). Rodriguez, in Brown, proposes a counter-genealogy of the hegemonic language by defining it in terms of a creative encounter between two cultures where the subjugated culture transforms the hegemonic one. Thus understood, American English becomes "brown," "impure" (xi). The process of transformation initiated by African 
slaves' appropriation of the dominant language and the cultural hybridity that ensues serve as a paradigm for an understanding of the "browning of America." This celebration of cultural, racial, and linguistic hybridity builds on Rodriguez's refusal of essentialist categories of origins which are already to be found in Hunger.

38. Randy A. Rodríguez suggests that "perhaps Rodriguez's understanding and use of 'American' as a self-description is more complicated than the assimilative derogatory his critics would assert" (411). Even though I sympathize with this possibility I remain skeptical. Rodriguez's use of 'American' seems too tightly intertwined with his conservative textual voice and the telos of social progress that pertains to it. It is true, however, that his subsequent works imply a reconceptualization of the monolithic signifier 'American' in the terms indicated by Randy Rodríguez.

39. The linguistic distinction I delineate following Rodriguez can be implemented by Mary Douglas who, following Basil Bernstein, establishes a distinction between "elaborated" and "restricted code." The latter is a "code which does not facilitate the verbal communication of meaning ... It is a code where changes in meaning are more likely to be signaled non-verbally than through changes in verbal selection" (Bernstein qtd. in Douglas, 45). On the other hand, the elaborated code's "primary function is to organize thought processes, distinguish and combine ideas" (Douglas, 44).

\section{WORKS CITED}

Alarcón, Norma. "Tropology of Hunger: The 'Miseducation' of Richard Rodriguez." The Ethnic Canon: Histories, Institutions and Interventions. Ed. Palumbo-Liu, David, Minneapolis: U of Minnesota P, 1995, 140-52.

Anzaldúa, Gloria. Borderlands/La Frontera: The New Mestiza. San Francisco: Aunt Lute, 1987.

Braidotti, Rosi. "Becoming Woman: or Sexual Difference Revisited." Theory, Culture \& Society 20.3:43-64.

Burke, Carolyn. "Irigaray through the Looking Glass." Burke 37-56.

Burke, Carolyn, Naomi Schor, and Margaret Whitford, eds. Engaging with Irigaray. Feminist Philosophy and Modern European Thought. New York: Columbia UP, 1994.

Butler, Judith. Bodies That Matter. On the Discursive Limits of "Sex." New York: Routledge, 1993.

_. "Bodies That Matter." Burke 141-74.

- Gender Trouble. Feminism and the Subversion of Identity". New York: Routledge; 1990.

De Castro, Juan E. "Richard Rodriguez in 'Borderland': The Ambiguity of Hybridity." Aztlán 26. (2001): 101-26.

De Certeau, Michel. The Practice of Everyday Life. Trans. Steven F. Rendall. Berkley: U of California P, 1984.

Deleuze, Gilles, and Guattari Félix. Kafka. Toward a Minor Literature. Trans. Dana Polan. Minneapolis: U of Minnesota P, 1986.

Dollimore, Jonathan. "Desire and Difference. Homosexuality, Race, Masculinity." Stecopoulos, 17-44.

—. Sex, Literature and Censorship. Cambridge: Polity P. 2001. 
Douglass, Mary. Natural Symbols. Explorations in Cosmology. London: Barrie \& Jenkins, 1970.

Firmat, Gustavo Pérez. "Richard Rodriguez and the Art of Abstraction." Colby Quarterly 32.4 (1996): 255-66.

Flores, Lauro. "Culture, Ideology and Self." The Americas Review 18.2 (1980): 80-91.

Fuss, Diana. Identification Papers. New York, London: Routledge. 1995.

- "Inside/Out." inside/out. Lesbian Theories, Gay Theories. Ed. Diana Fuss. New York, London: Routledge, 1991: 1-10.

Gallop, Jane. Thinking Through the Body. New York: Columbia UP, 1988.

Hall, Stuart. "New Ethnicities." Identities. Eds. Linda Martín Alcoff, Eduardo Mendieta. Oxford: Blackwell, 2003, 90-95.

Irigaray, Luce. Speculum of the Other Woman. Trans. Gillian G. Gill. Ithaca, New York: Cornell UP, 1985.

—. This Sex Which Is Not One. Trans. Catherine Porter. Ithaca, New York: Cornell UP, 1985.

Muñoz, José Esteban. Disidentifications. Queers of Color and the Performance of Politics. Cultural Studies of the Americas v.2. Minneapolis, London: U of Minnesota P, 1999.

Renny, Christopher. "Rags to Riches to Suicide: Unhappy Narratives of Upward Mobility: Martin Eden, Bread Givers, Delia's Sons, and Hunger of Memory." College Literature 29.4 (2002): 79-108.

Rivera, Tomás. "Hunger of Memory as Humanistic Antithesis." MELUS 11.4 (1984): 5-13.

Rodríguez, Randy A. “Richard Rodriguez Reconsidered: Queering the Sissy (Ethnic) Subject." TSLL 40.4 (1998): 396-423.

Rodriguez, Richard. Brown. The Last Discovery of America. New York: Viking, 2002.

- Days of Obligation: An Argument with My Mexican Father. New York: Viking, 1992.

- Hunger of Memory: The Education of Richard Rodriguez. New York: Bantam, 1982.

—_. "I don't think I exist": Interview with Richard Rodriguez. By Hector A. Torres. Melus 28.2 (Summer 2003): 164-202.

—. "Violating the Boundaries: An Interview with Richard Rodriguez." By Timothy S. Sedore. Michigan Quarterly Review 38.3 (1999): 425-46.

Saldívar, José David. Border Matters. Remapping American Cultural Studies. Berkley: U of California P, 1997.

—. The Dialectics of Our America. Genealogy, Cultural Critique, and Literary History. Durham, London: Duke UP, 1991.

Saldívar, Ramón. "Ideologies of Self: Chicano Autobiography." Diacritics 15.3 (1985): 25-35.

- Chicano Narrative. The Dialectics of Difference. Madison: The U of Wisconsin P, 1990.

Schor, Naomi. "Previous Engagements: The Reception of Irigaray." Burke 3-14.

Sheller, Mimi, and John Urry. "Mobile Transformations of 'Public' and 'Private' Life." Theory, Culture E Society 20.3: 107-125.

Staten, Henry. "Ethnic Authenticity, Class, and Autobiography: The Case of Hunger of Memory." In PMLA 113.1 (1988): 103-15. 
Nietzsche's Voice. New York. Cornell UP, 1990.

Uebel, Michael. "Men in Color: Introducing Race and the Subject of Masculinities." Race and the Subject of Masculinities. Eds. Harry Stecopoulos, Michael Uebel. Durham, London: Duke UP, 1997.

Whitford, Margaret. "Reading Irigaray in the Nineties." Burke 15-33. 